\title{
Conceptual bases of intensification of mining operations in mines of Ukraine based on monitoring and condition management of mine hoisting systems
}

\author{
Serhii Ilin $^{1}$, Larysa Adorska ${ }^{1, *}$, Volodymyr Samusia ${ }^{2}$, Dmytro Kolosov ${ }^{2}$, and Inna Ilina ${ }^{2}$ \\ ${ }^{1}$ Institute of Geotechnical Mechanics named by N. Poljakov of National Academy of Sciences of \\ Ukraine, 49005, Dnipro, Simferopolska Str., 2a, Ukraine \\ ${ }^{2}$ Dnipro University of Technology, 49005, Dnipro, D. Yavornytskoho Ave., 19, Ukraine
}

\begin{abstract}
The article justifies technical and organizational solutions aimed at improving the operational properties of hoisting equipment, the development of methods and means of controlling the operational state of existing systems in complex mining-geological and mining-engineering conditions. Technical solutions of a new type of hoisting machines with two consecutive friction pulleys, which have significantly higher load characteristics and allow usage of less metal-intensive and energyintensive hoisting machines, are considered. The order of estimation of a state of a mine shaft and general types of work on its monitoring are justified. Conceptual foundations of intensification of mining operations in the mines of Ukraine are defined based on modernization of hoisting equipment units and improvement of a control system.
\end{abstract}

\section{Introduction}

At the present time, under the conditions of limitation of financial, material and mineral resources, it is expedient to intensify underground mining operations through technical reequipment of main production processes and introduction of new non-traditional and safe technologies for development of coal seams. This provides a significant increase in operation efficiency of mines, resource saving and quality of coal products and leads to an improvement of the key indicator of coal competitiveness - its prime cost. Primary tasks here are the development and implementation of new non-traditional methods of condition management of geotechnological systems, which can ensure the intensification of operation of mining enterprises, considering the requirements of labor safety and resource saving [1, 2].

There are great potential resources to ensure the intensification of mining operations in the improvement of mine hoisting systems:

- increase the speed of hoisting to increase the amount of minerals hoisted to the surface as the main indicator of mine productivity;

- reduction of equipment and reinforcement wear to increase their life cycle;

- reduction of risks of accidents to reduce downtime and repair costs and eliminate the consequences of accidents.

\footnotetext{
*Corresponding author: adors@i.ua
} 
This is achieved through realization of two directions: modernization of hoisting equipment units, which radically increase operational properties of mine hoisting installations and development of methods and means of monitoring and managing the operational condition of existing systems.

In the first direction, the most promising solutions should be considered, including the installation, instead of the traditional, of a new type of hoisting machines, having two friction pulleys consecutively working for one rubber-cable rope (pack of ropes). Pulleys are electrically interconnected by one control system and steel traction ropes are replaced by rubber-cable ropes (RCR), that have significantly higher loading characteristics and allow using less metal-intensive and energy-intensive hoisting machines. Such systems are able to operate from depths that significantly exceed the currently boundary depth of 1600 $\mathrm{m}$. At the same time, the increased traction ability of paired friction pulleys in some cases stops using ballast balancing ropes, which create significant difficulties in operation. A kinematic scheme of a hoisting installation with two consecutive friction pulleys is shown in Figure 1.

It should be noted that such a system is much more secure by the criterion of the emergency danger of a local slipping of RCR along the pulleys. Unlike traditional machines with plastic lining of grooves under profiled steel ropes, which wears out, melts and loses traction when slipping, RCR grooves have a smooth steel or wear-resistant friction surface connected by friction forces with a smooth rubber surface of the RCR. In case of short-term local slipping, for example, in case of emergency braking, destruction of a pulley and the $\mathrm{RCR}$, there is no dangerous decrease in the friction coefficient.

When operating a hoisting unit with paired friction pulleys, each of them must be provided with standard reserves for non-slipping $K_{1}, K_{2}$ in Euler conditions. $K_{1}=K_{2}=1.25$ for gearless drive of a mine hoisting machine and $K_{1}=K_{2}=1.20$ for machines with a reducer.

The main scientific problems, the solution of which is necessary to ensure the efficiency of such installations, are:

- calculation of a required distribution of traction moments between the pulleys by the control system, which would ensure the preservation of a defined margin of non-slipping along each pulley;

- calculation of a complex stress-strain state of the rubber-cable construction and determination of rational parameters of a new type of traction element [3 - 7].

The second direction does not require large capital expenses. However, its development requires significant organizational efforts and scientific developments. It is oriented on existing hoisting systems, for which it is necessary to ensure the intensification of mining operations in the mines of Ukraine based on the use of monitoring systems for deep shafts. It lays a scientific and methodological basis for the formation of a strategy and plans of development for integrated survey and risk estimation during the operation of mine hoisting complexes of ore-hoisting shafts of Ukraine in order to ensure efficient and reliable operation of mine hoisting in conditions of intensification of mining operations during the transition to large depths of extraction while simultaneously increasing the level of operational safety. In the second direction, ensuring the safety of operation of mine hoisting installations of a new and traditional type is based on the creation of a monitoring system and assumes the development and application of a set of methods that provide receiving, processing and analyzing information about the status of hoisting equipment.

The relevance of creation and implementation of the system is due to negative trends in annual increase in risks of operation of mine hoisting machines, due to the complication of mining-geological and mining-technical conditions of operation of mine hoisting combined with long life cycles of shafts $[8,9]$. 


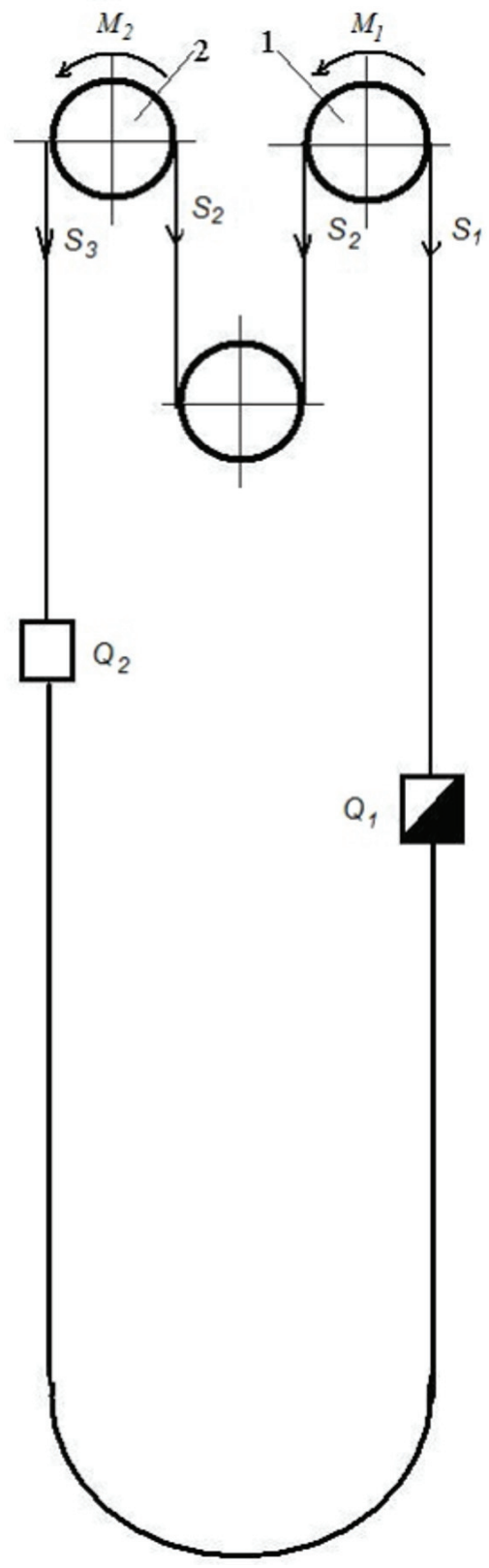

Fig. 1. Scheme of a new type of hoisting installation with two consecutive friction pulleys: $S_{1}-$ loaded rope tension, $\mathrm{N} ; S_{2}$ - intermediate rope tension without deflecting pulley inertia, N; $S_{3}$ - nonloaded rope tension, $\mathrm{N} ; M_{1}, M_{2}-$ driving pulley traction moments, $\mathrm{N} \cdot \mathrm{m}$.

\section{Methods}

Calculation of distribution of traction moments between the pulleys and a stress-strain state of the rubber-cable construction is ensured by fulfilling the following inequalities:

$$
\frac{S_{1}}{S_{2}} \leq \frac{\exp \left(\alpha_{1} \cdot f_{1}\right)}{K_{1}} ; \quad \frac{S_{2}}{S_{3}} \leq \frac{\exp \left(\alpha_{2} \cdot f_{2}\right)}{K_{2}} ;
$$


where $-\alpha_{1}, \alpha_{2}$ angles of contact with a rope of the first and second pulley correspondingly, $\operatorname{rad} f_{1}, f_{2}$ - coefficients of rope friction along the first and second pulley correspondingly.

According to the condition of non-slipping along the second pulley the maximum allowable stress of the intermediate rope $S_{2}$ is

$$
S_{2}^{\max }=S_{3} \cdot \frac{\exp \left(\alpha_{2} \cdot f_{2}\right)}{K_{2}}
$$

Accordingly, the maximum allowable tension of the loaded rope $S_{1}$, while fulfilling the condition of non-slipping on the first pulley and considering (2), is equal to:

$$
S_{1}=S_{3} \frac{\exp \left(\alpha_{1} \cdot f_{1}+\alpha_{2} \cdot f_{2}\right)}{K_{1} \cdot K_{2}}
$$

From (3), the equivalent margin of non-slipping of a paired hoisting machine is equal to the product of margins on non-slipping along each traction pulley. That is, such a hoisting machine has an equivalent margin against emergency slipping simultaneously for two pulleys which is much larger than the margin for each pulley individually and than a traditional hoisting machine with one driving pulley.

Calculate what should be the distribution of traction moments on the pulleys, in order to ensure the fulfillment of the conditions (1):

$$
M_{1}=R_{1} \cdot\left(S_{1}-S_{2}\right) ; \quad M_{2}=R_{2} \cdot\left(S_{2}-S_{3}\right) ;
$$

where $R_{1}, R_{2}$ - radii of driving pulleys, $\mathrm{m}$.

By substituting values of tensions $S_{1}$ and $S_{2}$ from (2) and (3) into (4) get the following:

$$
\begin{gathered}
M_{1}=R_{1} \cdot S_{3}\left[\frac{\exp \left(\alpha_{1} \cdot f_{1}+\alpha_{2} \cdot f_{2}\right)}{K_{1} \cdot K_{2}}-\frac{\exp \left(\alpha_{2} \cdot f_{2}\right)}{K_{2}}\right] \\
M_{2}=R_{2} \cdot S_{3}\left[\frac{\exp \left(\alpha_{2} \cdot f_{2}\right)}{K_{2}}-1\right]
\end{gathered}
$$

Relations (5) indicate that rope non-slipping along each of the driving pulleys can only be ensured by providing an unequal distribution of traction moments between them by the control system, determined by the following dependency:

$$
K_{M 12}=\frac{M_{1}}{M_{2}}=\frac{R_{1} \cdot\left[\frac{\exp \left(\alpha_{1} \cdot f_{1}+\alpha_{2} \cdot f_{2}\right)}{K_{1} \cdot K_{2}}-\frac{\exp \left(\alpha_{2} \cdot f_{2}\right)}{K_{2}}\right]}{R_{2} \cdot\left[\frac{\exp \left(\alpha_{2} \cdot f_{2}\right)}{K_{2}}-1\right]}
$$

If driving pulleys have equal radii $R$, angles of contact $\alpha$, friction coefficients $f$ and nonslipping margins $K$, then the relation of traction moments between them is determined from the equation:

$$
K_{M 12}=\frac{\left[\frac{\exp (2 \alpha \cdot f)}{K^{2}}-\frac{\exp (\alpha \cdot f)}{K}\right]}{\left[\frac{\exp (\alpha \cdot f)}{K}-1\right]}
$$


From the relation (7) it can be seen that the ratio of traction moments along the pulleys, which ensures the absence of inelastic slipping of ropes with equal margins on each pulley, does not depend on the current values of tension in the machine ropes. That is, it does not depend on its type (balanced or unbalanced), on the position of the hoisting vessels in the shaft, and when radii of the pulleys are equal neither depends on their radius. It can be seen that this value depends only on angles of contact of the pulleys, friction coefficients and defined margins for non-slipping. Therefore, it is an invariant of a change of tension of ropes, a degree of balance of the hoisting installation, a weight of hoisting vessels and a presence or absence of lower balancing ropes. This makes it possible to implement a sufficiently reliable control of its operation, both in the normal mode of operation and when the emergency brake is triggered, ensuring that the rope does not slip along any of the pulleys with a required margin.

Determine the maximum possible loading capacity of such an installation according to the criterion of ensuring the friction connection of a rope with pulleys with a given margin of non-slipping. The most dynamic mode of operation of a hoisting machine is the triggering of a safety (emergency) brake during the descent of the load.

Consider this process for the most general variant of a partially balanced hoisting installation with different weights of head and balancing ropes in operating and emergency dynamic modes. In this case static $S_{1}^{s t}, S_{3}^{s t}$ and dynamic $S_{1}^{\text {din }}, S_{3}^{\text {din }}$ tensions of branches of a rope are equal to

$$
\begin{gathered}
S_{1}^{s t}=\left[Q_{g r}+q \cdot(H-l)+q_{u r} \cdot l\right] ; \quad S_{1}^{d i n}=S_{1}^{s t} \cdot\left(1-\frac{W}{g}\right) \\
S_{3}^{s t}=\left[Q_{p o r}+q \cdot\left(l+l_{0}\right)+q_{u r} \cdot\left(H-l-l_{0}\right)\right] ; \quad S_{3}^{d i n}=S_{3}^{s t} \cdot\left(1+\frac{W}{g}\right) ;
\end{gathered}
$$

where $W$-deceleration during braking, $\mathrm{m} / \mathrm{s}^{2}, g-$ free fall acceleration, $\mathrm{m} / \mathrm{s}^{2} ; H$ - length of a rope from a pulley to a loading device at a shaft bottom, m; $q$ - weight of a unit length of a head rope, N/m; $Q_{g r}$ - weight of a loaded hoisting vessel, N; $Q_{p o r}-$ weight of an empty hoisting vessel, $\mathrm{N} ; l-$ path of the vessels covered from the beginning of the ascension cycle, $\mathrm{m} ; l_{0}$ - distance from a pulley to a level of the upper position of a hoisting vessel in a shaft, $\mathrm{m}$.

Deceleration during the emergency braking in a mine hoist with a friction pulley is limited by an allowable value according to a non-slipping condition. The minimum value of this deceleration is allowed to be equal to $1.2 \mathrm{~m} / \mathrm{s}^{2}$. In this case, the greater the deceleration value is permitted by the hoisting installation without the occurrence of rope slipping, the faster it stops and leaves the main emergency mode that caused the brake to trigger. This should be considered during a comparative analysis of characteristics of hoisting systems with different parameters.

By substituting expressions for $S_{1}^{\text {din }}$ and $S_{3}^{\text {din }}$ into (8) and (3) with equal pulley parameters, obtain an expression for determining the maximum allowable deceleration $W 2 S k_{\max }(l)$ of the hoisting vessel according to the non-slipping condition in the emergency breaking mode when the load is descending at any point of the shaft

$$
W 2 S k_{\max }(l)=\frac{S_{3}^{s t}(l) \cdot \exp (2 \alpha \cdot f)-K o b^{2} \cdot S_{1}^{s t}(l)}{S_{1}^{s t}(l) \cdot K o b^{2}+\exp (2 \alpha \cdot f) \cdot S_{3}^{s t}(l)}
$$

For a traditional hoisting installation with a single pulley maximum allowable deceleration [10]:

$$
W 1 S k_{\max }(l)=\frac{S_{3}^{s t}(l) \cdot \exp (\alpha \cdot f)-K o b \cdot S_{1}^{s t}}{S_{1}^{s t} \cdot K o b+\exp (\alpha \cdot f) \cdot S_{3}^{s t}(l)}
$$


The obtained relations are the basis for calculating the laws of electric drive and brake control of driving friction pulleys, loading capacity, allowable accelerations and decelerations that ensure reliable and safe operation of hoisting equipment with machines and tractive elements of a new type, considering inertial characteristics of pulleys, ropes, and vessels. Such modernization significantly improves their performance and loading capacity without changing the shaft equipment of hoisting complexes (provided that the value of the 'hoisting machine intensity' parameter meets the criteria of parametric stability of the dynamic interaction of a heavier hoisting vessel with reinforcement and reduces energy consumption during operation) [11].

\section{Results and discussion}

Applying relations (1) - (10), compare the possible values of allowable accelerations and loading capacities of double-drive and conventional hoisting machines with traditional parameter values for mine hoisting practice of deep ore-hoisting shafts: $\alpha=\pi$; calculated friction coefficient $f=0.25 ; K=1.25$; the amount of steel head ropes $n=8$; weight of an empty skip $Q_{p o r}=500 \mathrm{kN}$; diameter of head ropes $42 \mathrm{~mm}$; weight of a unit length of one head rope $77 \mathrm{~N}$ (weight of a unit length of all ropes $q_{u r}$ is equal to $77 \cdot 8=616 \mathrm{~N}$ ).

Radius of the driving pulley of a hoisting machine multirole $-5 \times 8$ is equal to $2.5 \mathrm{~m}$. RCR which is equivalent to eight steel head ropes by carrying capacity has a length unit weight of $q=637 \mathrm{~N} / \mathrm{m}$. At the same time, its design contains cables with a diameter of $21 \mathrm{~mm}$, packed into a rubber shell. Therefore, according to the criterion of maximum allowable ratio of the pulley diameter to the diameter of a steel rope/cable, the driving pulleys may have a radius $R=1.05 \mathrm{~m}$. The results of calculations by formulas (9), (10) for the traditional ratio of weights of hoisting vessels $\left(Q_{g r} / Q_{p o r}=2\right)$ and the equality of length unit weights of head and balancing ropes are shown in Figure 2. Graphs shown in Figure 2 show the dependencies of the allowable deceleration for a traditional installation (curve 1) and a paired hoisting installation of a new type (curve 2).

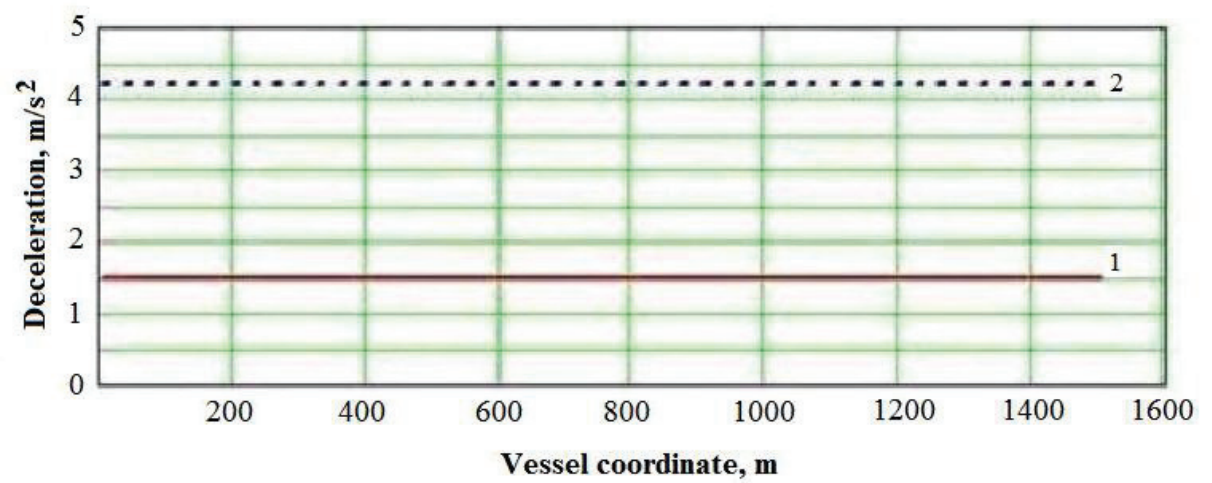

Fig. 2. Dependency of maximum allowable deceleration during the emergency braking in a mode of load descending on a position of vessels in a shaft: 1 - single pulley mine hoist; 2 - double hoist mine hoist.

It can be seen that in this variant the paired hoisting machine provides 2.8 times safer deceleration than the traditional type of machine. Moreover, the value of this deceleration is the same at each point of the shaft. Select this value of deceleration to determine the maximum possible weight of a loaded vessel in a fully balanced paired hoisting machine. In the case of usage of lightened balancing ropes, the allowable deceleration during the emergency braking becomes a variable function of a shaft depth.

Figure 3 shows the graphs of allowable deceleration $W_{\max }$ for a paired hoisting machine on a length unit weight of a balancing rope for different points in a shaft. 


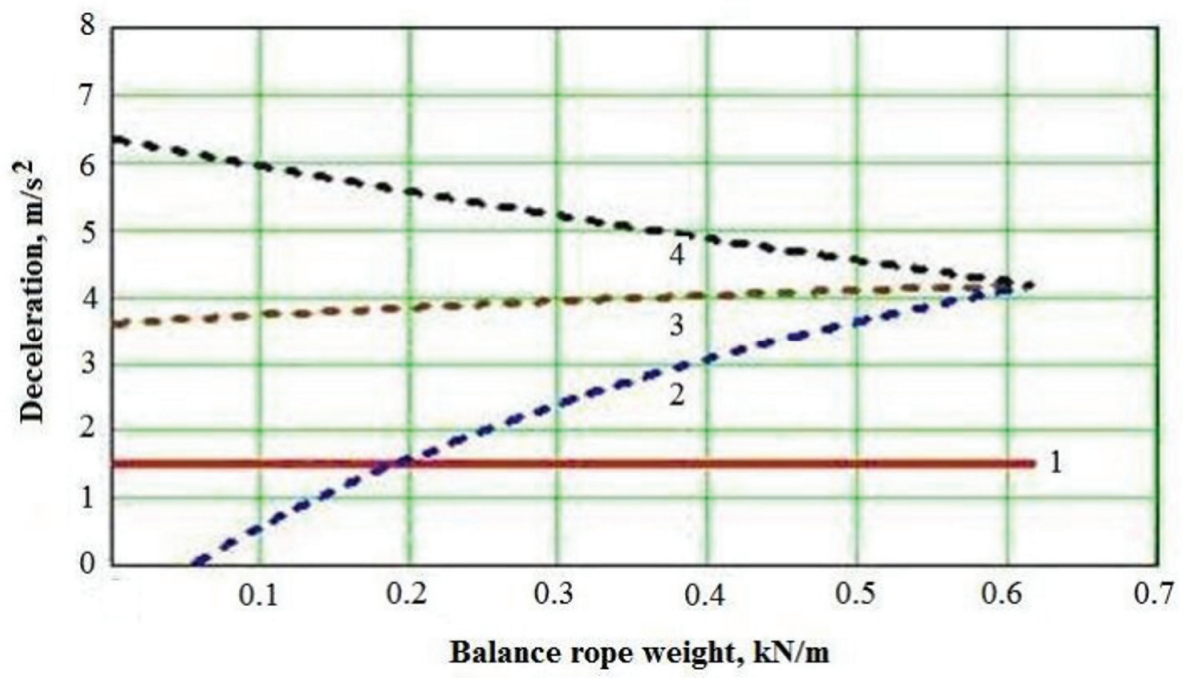

Fig. 3. Dependencies of allowable decelerations during the emergency braking on a weight of a balancing rope: 1 - single pulley mine hoist; 2 - shaft lifting machine with two pulleys at the bottom of the shaft; 3 - shaft lifting machine with two pulleys in the middle of the trunk; double-shaft mine hoist at the top of the shaft.

It can be seen that the allowable deceleration during the emergency braking in a mode of descending a load increases as a vessel ascends in a shaft. In addition, it is clear that only from $q_{u r}=0.2 \mathrm{kN} / \mathrm{m}$ the paired hoisting machine begins to exceed the traditional system in terms of the allowed deceleration and, as a result, in carrying capacity.

Figure 4 shows a graph of the allowable deceleration during the emergency braking on the weight of a loaded vessel for a fully balanced coupled hoisting machine.

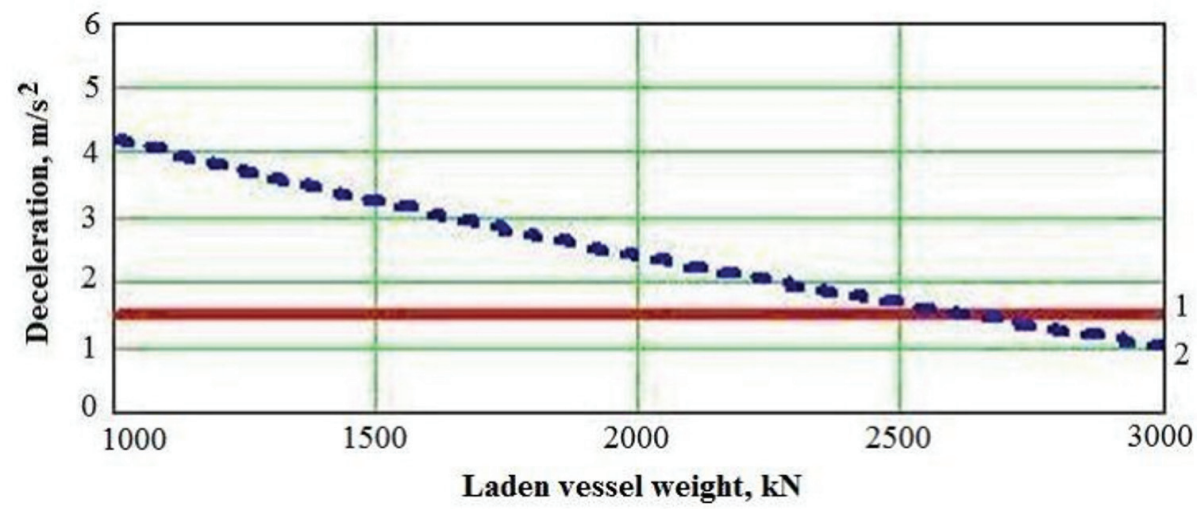

Fig. 4. Dependency of allowable deceleration on a weight of a loaded vessel: 1 - single pulley mine hoist; 2 - double hoist mine hoist.

It can be seen that the new hoisting machine exceeds the dynamic characteristics of a traditional one when the value of a weight of a loaded vessel is up to $2500 \mathrm{kN}$, which is several times more than the maximum load of existing installations.

Having performed the calculations by formulas (9), obtain that paired hoisting machine has a maximum allowable deceleration value of $W_{\max }=1.5 \mathrm{~m} / \mathrm{s}^{2}$ at a weigh of a loaded vessel 5.2 times larger than the weight of an empty one. It speaks of large reserves in a selection of carrying capacity, degree of balance, dynamic characteristics and safety when replacing traditional hoisting machines that have one friction pulley and steel head ropes with paired friction pulleys and rubber-cable head and balancing ropes. 
In this case, a number of new problems appear that require solution to ensure reliable operation of such systems. These are problems of ensuring lateral stability of rope winding through cylindrical pulleys, problems of optimal distribution of traction moments between pulleys at each point of the shaft, which depends on the relation of installation parameters, optimization of RCR design for operation under conditions of alternating tensile and bending dynamic deformations during winding through the system of pulleys, development of a system for monitoring the condition of both the ropes themselves and synchronization of operation of electric drives and hoisting machine brakes.

Solving the problem of monitoring the technical condition of mine hoists comes down to creating conditions that would establish the current state of equipment based on a comprehensive estimation of characteristics of all interrelated elements, make it possible to predict changes over time of this state and allowed to quickly determine the exact locations, sources and character of potential danger. On the basis of these data, the character, sequence, amount of work and the cost of resources for carrying out preventive maintenance and repair are determined [12]. In a general case it is required to perform a full range of the following activities:

- optical-visual survey of the shaft equipment, analysis of the results of instrumental measurements of guide profiling, measurements of wear of guides and buntons, assessment of safety of the shaft operation. Development of recommendations to improve the safety of operation of shafts;

- development of methodological support and instructive documentation for conducting measurements in industrial conditions on existing shafts, processing and analysis of results;

- performing measurements of movement smoothness of the hoist vessels, mathematical processing of instrumental measurement data, execution of deformation-strength calculations;

- development of complex mathematical models of dynamic processes in shaft equipment for diagnosis and prediction of development of negative processes (corrosion of buntons, wear, deformation of guides, etc.) in conditions of great hoisting depths and longterm service of shafts;

- justification of the criteria for ranking the levels of emergency hazard of operation of mine shafts during their long-term service.

Due to the fact that many parameters of various elements of the shaft are interrelated, the use of complex multifactor mathematical models and computer-oriented modeling methods in combination with measurement data of the parameters of an actual operating condition of the system makes it possible to determine the risk level of various phenomena and processes under the conditions of each specific shaft. This allows localizing reinforcement sections with an increased level of emergency hazard in the early stages and taking organizational and preventive measures to eliminate potential hazard [13 - 17].

\section{Conclusions}

Modernization of hoisting equipment by switching to machines with paired friction pulleys and rubber-cable head and balancing ropes allows increasing their loading capacity, reliability, performance and safety, and reducing energy consumption during operation. Rubber-cable traction ropes significantly exceed the traditionally used steel ropes by their characteristics and durability and can successfully replace them in the reconstruction or creation of new hoisting equipment.

Implementation of measures for monitoring the technical condition of hoisting systems, with appropriate scientific, technical, methodological and organizational support, allows achieving a qualitatively new level in solving the following relevant scientific and technical problems of the industry: 
- obtaining new objective information about the dependencies of physical and mechanical processes in mine hoisting systems during long-term operation in difficult mining and geological conditions;

- organization of a scientifically justified system of targeted preventive measures that minimize the risk of spontaneous accidents in shafts.

\section{References}

1. Ilin, S.R., Ilina, S.S., Samusia, V.I. (2014). Mine lifting mechanics. Mister of Education and Science of Ukraine, National Mining University

2. Ilin, S.R., Adorska, L.G., Samusia, S.V. (2014). Ensuring the safety of the mine rises in the shafts under complex mining and geological and mining conditions. Geotechnical mechanics: Interdepartmental collection of scientific papers IGTM NAS of Ukraine, $119,20-35$

3. Kolosov, D., Bilous, O., Tantsura H., Onyshchenko, S. (2018). Stress-strain state of a flat tractive-bearing element of a lifting and transporting machine at operational changes of its parameters. Solid State Phenomena, 277, 188-201

4. Kolosov, D., Dolgov, O., Kolosov, A. (2014). Analytical determination of stress-strain state of rope caused by the transmission of the drive drum traction. Progressive Technologies of Coal, Coalbed Methane, and Ores Mining, 499-504

5. Kolosov, D., Dolgov, O., Bilous, O., Kolosov, A. (2015). The stress-strain state of the belt in the operating changes of the burdening conveyor parameters. New Developments in Mining Engineering 2015: Theoretical and Practical Solutions of Mineral Resources Mining, 585-590

6. Belmas, I., Kolosov, D. (2011). The stress-strain state of the stepped rubber-rope cable in bobbin of winding. Technical and Geoinformational Systems in Mining: School of Underground Mining 2011, 211-214

7. Belmas, I.V. (1993). Stress state of rubber-rope tapes during their random damages. Problemy Prochnosti i Nadezhnosti Mashin, 6, 45-48

8. Ilin, S.R., Radchenko, V.K., Adorska, L.G. (2017). Risk-forming processes during the operation of mine hoisting installations. Geotechnical mechanics: Interdepartmental collection of scientific papers IGTM NAS of Ukraine, 134, 22-33

9. Ilin, S.R., Samusia, V.I., Kolosov, D.L., Ilina, I.S., Ilina, S.S. (2018). Risk-forming dynamic processes in units of mine hoists of vertical shafts. Naukovyi Visnyk Natsionalnoho Hirnychoho Universitetu, 5, 64-71

10. Guidelines for the calculation of the braking moment and the verification calculation for non-slip of the ropes in the modes of safety braking of hoisting machines with a friction pulley. (1984). USSR Ministry of Coal Industry. VNIIGM them. M.M. Fedorov. Donetsk

11. Method of calculating rigid reinforcement of vertical shafts. (1994). VNIIGM them. M.M. Fedorov. Donetsk

12. Diagnostics of the state of the systems of" attachment-array "and" lifting vessel-rigid reinforcement "of mine shafts. Procedure and method of execution. (2004). GR 3-0322004. Ministry of Industrial Policy of Ukraine

13. Ilin, S.R., Samusia, V.I., Ilina, I.S., Ilina, S.S. (2016). Influence of dynamic processes in mine hoists on safety exploitation of shafts with broken geometry. Naukovyi Visnyk Natsionalnoho Hirnychoho Universitetu, 3, $42-47$

14. Ilin, S.R., Samusia, V.I., Ilina, I.S., Ilina, S.S. (2015). Influence of dynamic processes in mine winding plants on operating safety of shafts with broken geometry. Theoretical and practical solutions of mineral resources mining. Taylor \& Francis group. 425-429

15. Bondarenko, V.I., Samusia, V.I., Smolanov, S.N. (2005). Mobile lifting units for wrecking works in pit shafts. Gornyi Zhurnal, 5, 99-100 
16. Ilin, S.R., Adorska, L.G., Posled, B.S. (2011). Measuring and analytical computer technology for diagnosing and managing the condition of equipment in mine lifting complexes. Geotechnical mechanics: Interdepartmental collection of scientific papers IGTM NAS of Ukraine, 93, 28-38

17. S.R. Ilin, L.G. Adorska, V.K. Radchenko, B.S. Posled, I.S. Ilina, S.S. Ilina. (2013). The Experience Of Dynamic Apparatus Control And Estimation Of Exploitation System Safety "Vessel - Reinforcement" Of Vertical Mining Shafts. Transport szybowy. Instytut Techniki Gornicej 